\title{
Functional Morphological Drivers of Feeding Mode in Marine Teleost Fishes
}

\author{
Matthew J. Sonnefeld", Ralph G. Turingan, Tyler J. Sloan \\ Department of Biological Sciences, Florida Institute of Technology, Melbourne, 32901, Florida, United States \\ *Corresponding Author: msonnefeld2008@my.fit.edu
}

Copyright $@ 2014$ Horizon Research Publishing All rights reserved.

\begin{abstract}
It is well known that the feeding mode of fish falls within a continuum of prey-capture techniques and behaviors; fish could use suction, ram, or manipulation styles to feed on a subset of a diverse prey-resource base. The main goal of ecomorphological research is to model the relationship between form and function, and in the case of fish feeding, one of the key questions is, "How does the functional design of the feeding mechanism constrain fish to a particular feeding mode?" This study initially addresses this question by conducting a multivariate analysis to determine which of the key functional components of the feeding mechanism predicts the feeding mode of teleost fishes along the Atlantic coast of Florida (USA). Sixteen feeding-relevant traits from each of 22 species were subjected to a Principal Component Analysis to generate a morphospace for the assemblage. The first two dimensions contributed $99 \%$ of the variation in functional morphology among members of this assemblage; the physiological cross-sectional area of the epaxialis muscle loaded heavily in these axes. A Discriminant Function Analysis revealed that the drivers that discriminate the assemblage among suction, ram, and manipulation feeding modes are Suction Index, mechanical advantage of the jaws, and mechanical advantage of neurocranial rotation. The model revealed that $91 \%$ of the species' feeding modes were correctly predicted by properties of the feeding mechanism. Appropriately establishing the link between morphology and ecology remains a valuable tool in our continuing search for information that advances our understanding of the underlying mechanisms that drive the diversity and evolution of feeding systems.
\end{abstract}

Keywords Ecomorphology, Multivariate, Morphospace

\section{Introduction}

Establishing the link between morphology and ecology (ecomorphology) has long been a major goal of organismal biologists. This goal has been commonly addressed by demonstrating the strength of the correlation between relevant morphological (e.g., gape, bone and muscle size) and ecological (e.g., proportion of prey found in the guts) traits of the organism. [1-5]. A consensus among ecomorphologists is that constraints on function shape the relationship between morphology and ecology $[1,2,5]$. In fish-feeding the magnitude of these functional constraints are determined by the properties of the feeding apparatus. The rationale for ecomorphological research is the need to define how these constraints determine the food habits of fishes in a given environment. Our ability to understand how patterns of prey use are shaped advances our understanding of trophic dynamics, in particular, on population and community structure $[2,3]$. This study was designed to contribute to this need.

Teleost fishes employ three modes of prey-capture: Ram, Suction, and Manipulation. Each of these is closely associated with the functional morphology of the feeding apparatus (See Appendix 2), prey use, and behavior. In ram feeding the fish swims toward its prey and engulfs it using its relatively large mouth. The feeding mechanism of ram-feeding fishes is characterized by non-robust oral jaws, large gape, moderate suction ability, low mechanical advantage for jaw-closing, and moderate force-generating capability of the muscles $[5,6]$. Ram feeders eat free swimming prey such as squid and other fishes. Suction-feeding fishes generate a negative pressure in the buccal cavity prior to mouth-opening; prey is drawn into the mouth soon after the jaws open. The feeding mechanism of suction feeders is characterized by having a small gape, low mechanical advantage for jaw-closing, powerful force-generating capability of jaw-opening muscles and high suction ability [5-8]. These fishes feed on soft, substrate-attached or elusive prey such as shrimp and small crabs along with other fishes. Manipulation feeders crush or tear their prey using their feeding apparatus that is characterized by robust oral jaws, small gape, high mechanical advantage for jaw-closing, and a powerful force-generating capability of the adductor mandibulae. Manipulators feed on hard shelled prey such as mussels, barnacles, and crabs $[2,5,6]$.

The feeding mechanism in teleost fishes is composed of a 
complex suite of muscles and connective tissues associated with mostly kinetic bones, and organized into mechanical linkages that provide movement in the whole system [6]. This complex, functional organization underscores the need to address the question, "Which of the feeding-relevant functional-morphological characteristics underlie the designation of fishes into one of the three feeding modes described above?" We address this question with the seldom used, but believed to be effective and elegant, multivariate statistical tools in establishing the link between morphology and ecology using empirical data. First, we used Principal Components Analysis to reduce the dimensionality of the morphology-feeding mode correlation matrix and generate a morphospace that illustrates how the key components of the feeding apparatus influence the functional-morphological relationship among species. Second, we subjected the data to a Discriminant Function Analysis to corroborate the functional morphological traits that best discriminate the fishes among the three feeding modes as described above. Feeding modes were identified based on food-habit data generated in this study, and confirmed using the scheme available in the literature.

\section{Materials and Methods}

\subsection{Collection of Fishes}

In this study twenty-two species from nine families of fishes were collected by hook and line fishing off the coast of Jupiter, Florida (USA) in the spring of 2012. Species were collected at depths ranging from $10 \mathrm{~m}$ to $70 \mathrm{~m}$ and were put on ice directly after capture. These included Haemulidae (Haemulon aurolineatum , Haemulon plumieri, and Haemulon sciurus), Lutjanidae (Lutjanus synagris, Lutjanus analis, Lutjanus griseus, and Ocyurus chrysurus), Serranidae (Centropristis striata, Epinephalus drummondhayi, and Myctoperca microlepis ), Sparidae (Calamus penna, Calamus bajonado, Calamus proridens, and Pagrus pagrus), Balistidae (Balistes veltula), Batrachoididae (Opsanus tau), Carangidae (Caranx ruber and Seriola dumerili), Coryphaenidae (Coryphaena hippurus), Rachycentridae (Rachycentron canadum), and Scombridae (Euthynnus alletteratus and Scomberomorus maculatus).

\subsection{Food Habits}

All specimens had their standard length measured and stomachs removed shortly after being caught. The stomachs were fixed in $10 \%$ formalin solution for two weeks before contents were removed and each food item identified to the lowest possible taxon. All species were assigned a feeding mode based on prey use data gathered from the gut-content analysis, and various literature sources. Table 1 shows the prey use and assigned feeding mode of each of the species. The heads were severed at the first vertebra, and frozen before being dissected and measured.

Table 1. Food habits and feeding modes of study species

\begin{tabular}{|c|c|c|c|c|c|c|c|}
\hline Species & Species Key & Feeding Mode & Food Habits & Species & $\begin{array}{l}\text { Species } \\
\text { Key }\end{array}$ & $\begin{array}{l}\text { Feeding } \\
\text { Mode }\end{array}$ & Food Habits \\
\hline Balistes vetula & (Bv) & Manipulation & $\begin{array}{l}\text { Echinoids, Pteropods, } \\
\text { Gastropods [9] }\end{array}$ & Lutjanus analis & (La) & Ram & $\begin{array}{l}\text { Crabs, Fishes (Acanthurus, Diodon, } \\
\text { Gobiid) [9] }\end{array}$ \\
\hline Haemulon sciurus & (Hs) & Manipulation & Crabs, Pelecypods, Shrimp [9] & Lutjanus griseus & (Lg) & Ram & Crabs, Fishes, Shrimp [9] \\
\hline Haemulon plumieri & (Hp) & Manipulation & Crabs, Polychaetes, Echinoids [9] & Lutjanus synagris & (Ls) & Ram & Crabs, Stromatopods [9] \\
\hline Calamus bajonado & (Cb) & Manipulation & $\begin{array}{l}\text { Echinoids, Crabs, Pelecypods, } \\
\text { Gastropods [9] }\end{array}$ & Ocyurus chrysurus & (Oc) & Ram & Crabs, Shrimp, Fishes [9] \\
\hline Calamus penna & (Cp) & Manipulation & $\begin{array}{l}\text { Crabs, Gastropods, Brittle Stars } \\
\text { [9] }\end{array}$ & $\begin{array}{l}\text { Rachycentron } \\
\text { canadum }\end{array}$ & (Rc) & Ram & Fishes (Lactophrys) [9] \\
\hline Calamus proridens & (Cd) & Manipulation & Crabs, Fishes, Shrimp [10] & \begin{tabular}{|l} 
Euthynnus \\
alletteratus
\end{tabular} & (Ea) & Ram & Fishes (Jenkinsia), Squid [9] \\
\hline Pagrus pagrus & (Pp) & Manipulation & $\begin{array}{l}\text { Fishes, Polychaetes, Echinoids } \\
\text { [11] }\end{array}$ & $\begin{array}{l}\text { Scomberomorus } \\
\text { maculatus }\end{array}$ & (Sm) & Ram & Fishes (Etrumeus), Squid [13] \\
\hline Opsanus tau & (Ot) & Manipulation & Crabs, Moluscs, Shrimp [10] & \begin{tabular}{|l} 
Haemulon \\
aurolineatum
\end{tabular} & (Ha) & Suction & Shrimp, Polychaetes [9] \\
\hline Caranx ruber & $(\mathrm{Cr})$ & Ram & $\begin{array}{l}\text { Fishes (Acanthurus, } \\
\text { Pomacentrus) [9] }\end{array}$ & $\begin{array}{l}\text { Centropristis } \\
\text { striata }\end{array}$ & (Cs) & Suction & Crabs, Stromatopods, Fishes [14] \\
\hline Seriola dumerili & (Sd) & Ram & Fishes (Calamus, Haemulon) [9] & \begin{tabular}{|l} 
Epinephelus \\
drummonhayi
\end{tabular} & (Ed) & Suction & Crabs, Shrimp, Fishes [10] \\
\hline Coryphaena hippurus & (Ch) & Ram & $\begin{array}{l}\text { Fishes (Exocoetids, Scomberids, } \\
\text { Carangids) [12] }\end{array}$ & $\begin{array}{l}\text { Mypteroperca } \\
\text { microlepis }\end{array}$ & $(\mathrm{Mm})$ & Suction & Fishes, Crabs $[10,15]$ \\
\hline
\end{tabular}




\subsection{Suction Feeding Capability}

All metrics (see Table 2 and Figure 1) necessary to calculate the Suction Index (i.e., a measure of the suction-feeding capability of fish $[16,17])$ were measured from freshly thawed specimens, the heads of the same individuals used in the gut-content analysis.

$$
\text { Suction Index }=\left(\operatorname{CSAepax} *\left(\mathrm{~L}_{\text {in }} / \mathrm{L}_{\text {out }}\right)\right)
$$

/(Gape Width*Buccal Length)

The Suction Index, a unitless number between zero and one that is proportional to the negative pressure generated in the buccal cavity of a fish, is a well-known predictor of suction-feeding capacity in centrarchid fishes $[16,17]$.

Table 2. Suction Index Measures

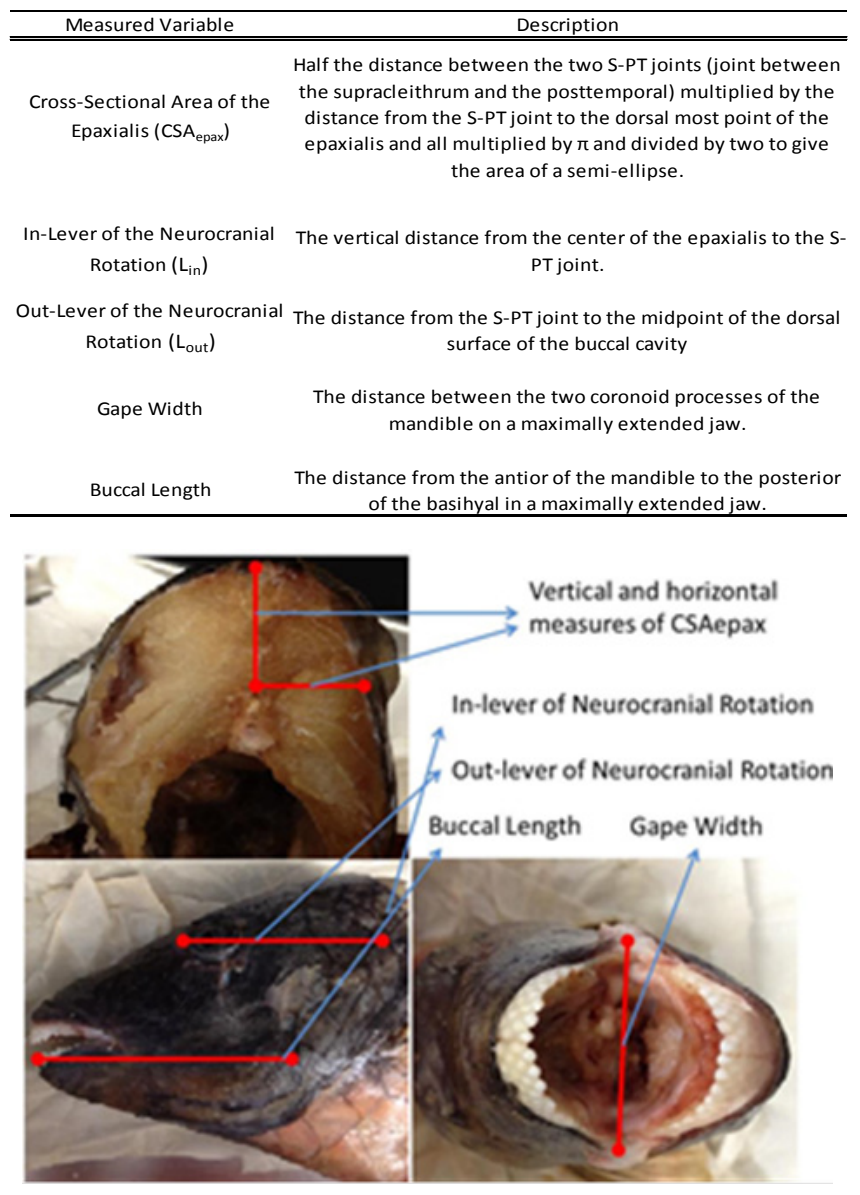

Figure 1. Images of suction index measures

\subsection{Force Generating Capability}

To measure the force generating capability of the adductor mandibulae complex and the sternohyoideus, the model developed by Calow and Alexander [18], and explained in Wainwright [1] was used:

Force Generating Capability $=(\mathrm{V} / \mathrm{w})^{*} \sigma * \sin (2 \theta)$

$\mathrm{V}$ is the muscle volume calculated using the mass and the standard density of fish muscles $\left(1.05 \mathrm{~g} / \mathrm{cm}^{3}\right)[1,19]$, $w$ is the width of the muscle, $\sigma$ is the constant of cross-sectional area force production taken from literature $\left(=200 \mathrm{kN} / \mathrm{m}^{2}\right.$ in teleost fishes) $[1,20,21]$, and $\theta$ is the average angle of muscle pinnation taken from three different points along the muscle. All measurements were performed using ImageJ software from photographs taken on an eight mega-pixel digital camera. Masses were taken using a Northern Balance and Scale R160-D analytical scale to the nearest hundredth of a gram. Force-generating capability of the adductor mandibulae complex represents half of the entire value for this bilaterally symmetrical muscle.

\subsection{Mechanical Advantage}

The mechanical advantage for jaw opening and closing was calculated using the equation:

Mechanical Advantage $=($ In-Lever $/$ Out-Lever $)$

Morphological markers used were the same as those in Wainwright and Richards [2]. The out-lever was measured as the distance from the center point of the articular-quadrate joint to the anteriormost point of the dentary. The distance from the center point of the articular-quadrate joint to the point of insertion of Meckel's cartilage at the medial depression on the dentary was the in-lever of closing and the distance from the center point of the articular-quadrate joint to the interoperculo-mandibular ligament's point of attachment on the angular was the in-lever for jaw opening. Measurements were made using Mitutoyo Digimatic dial calipers to the nearest hundredth of a millimeter. The mass of the cleaned jaws was also taken, using the same analytical scale as the muscles, to the nearest hundredth of a gram.

The ratio of in-lever to out-lever (= mechanical advantage) serves as an indication of the trade-off between force transmission to the tip of the jaw and speed of jaw rotation. High mechanical advantage indicates that a greater amount of muscle force is transmitted to the tip of the jaw at a slower speed of jaw rotation. Low mechanical advantage indicates that the speed of muscular contraction is magnified at the tip of the jaw, resulting in a relatively high speed of jaw rotation $[2,22,23]$. Assuming a consistent bone density, the mass of the oral jaws serves as an indicator of the resistance of the bone to compressive force, thus, fish that consume hard shelled prey have hypertrophied jaw bones relative to conspecifics that feed on soft prey.

\subsection{Statistical Treatment}

The species means (See Appendix 1) of each variable were subjected to a Principal Component Analysis (PCA) to identify the major contributors to variation in feeding functional morphology among feeding modes. This was followed by a Discriminant Function Analysis (DFA) to determine the grouping pattern and main discriminants of the three feeding modes. All statistics were performed using $\mathrm{R}$ statistical software [24] with the MASS package [25]. 


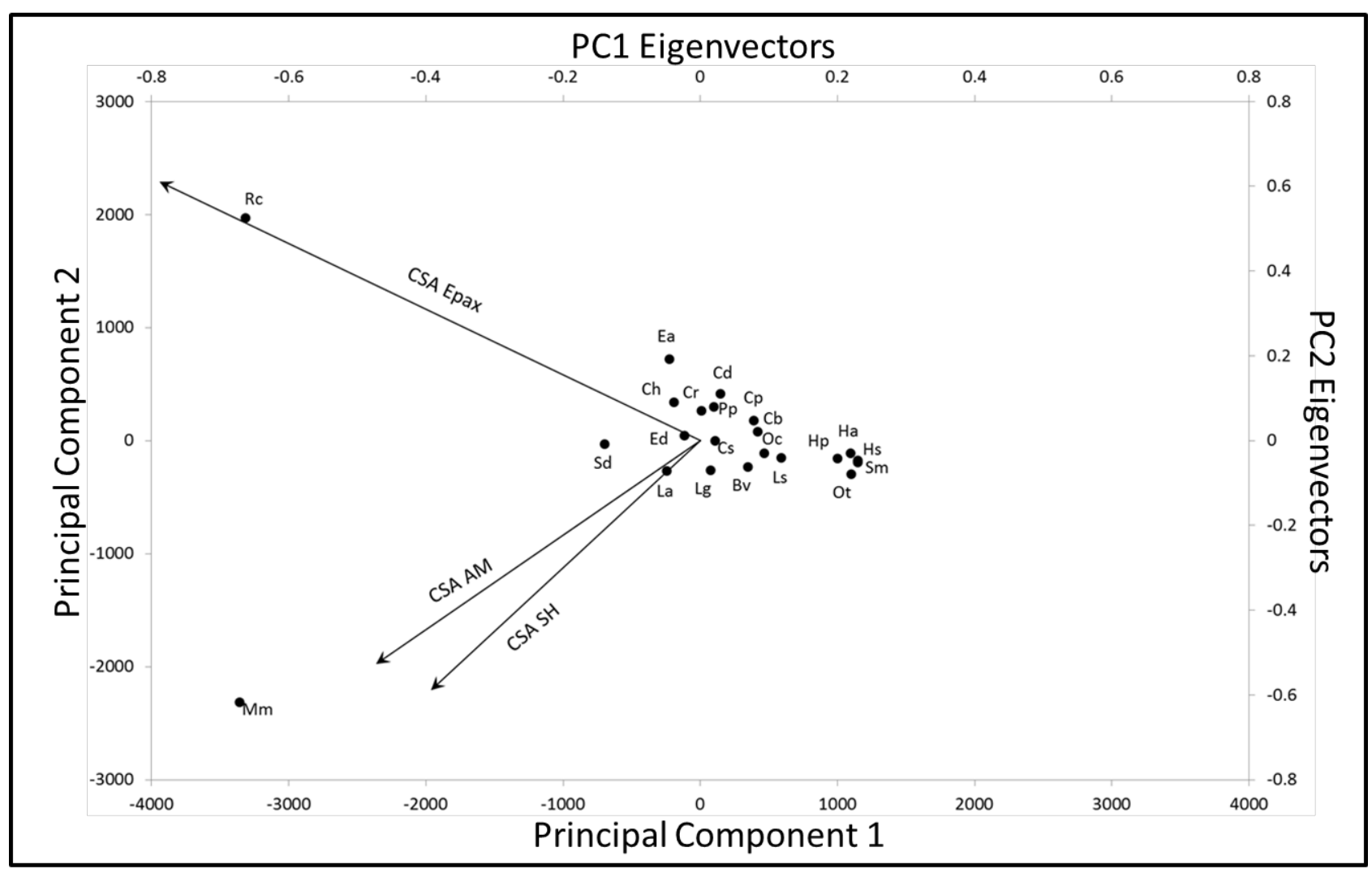

Figure 2. Morphospace generated from species means of the 16 morphological traits. Species key is in Table 1.

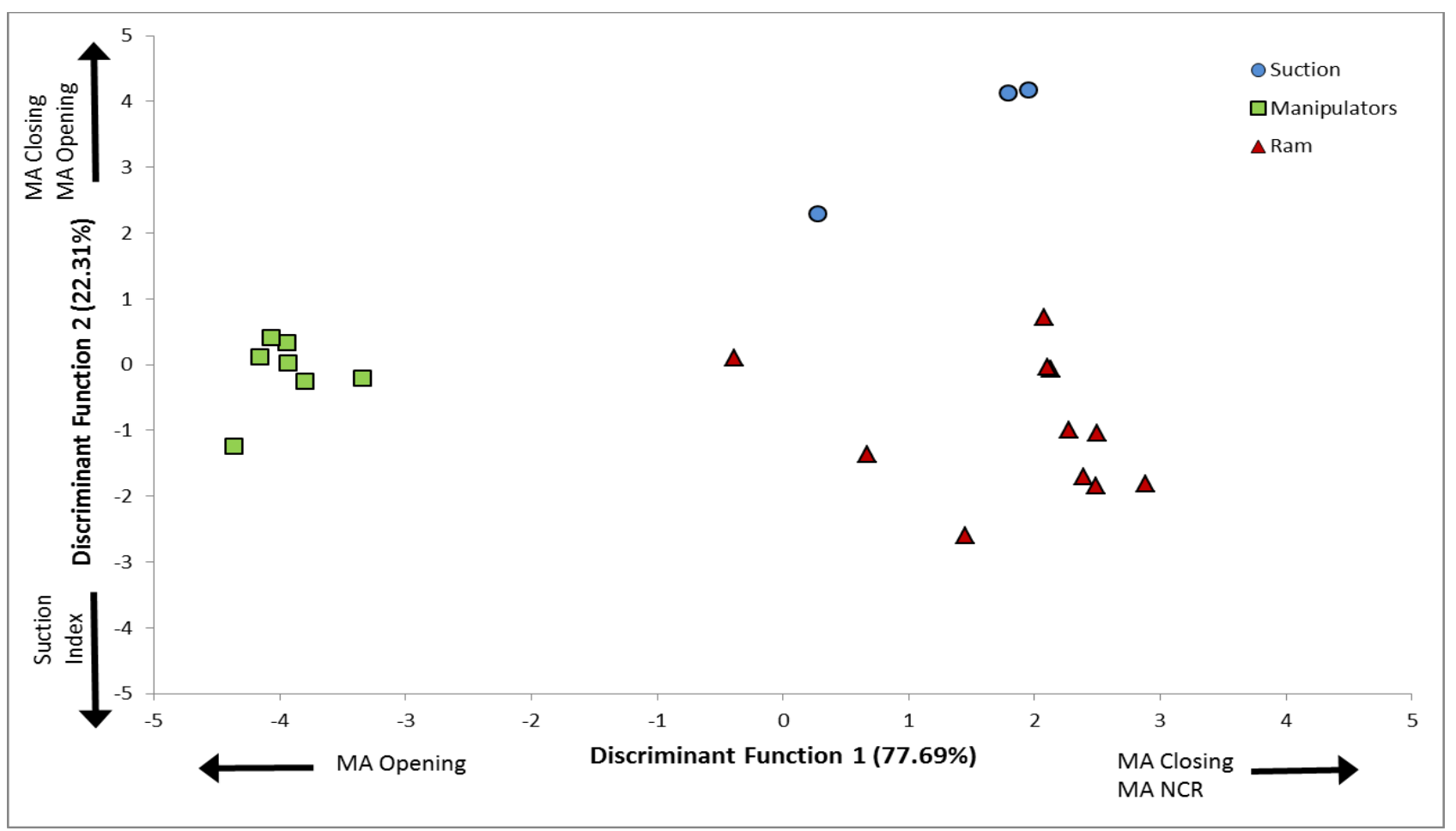

Figure 3. Discriminant function analysis plot of study species. MA = mechanical advantage and NCR $=$ neurocranial rotation. Species of each feeding mode form three distinct clusters 


\section{Results}

Principal Component Analysis of the sixteen morphological traits (Figure 2) revealed that $73.03 \%$ of the variance could be explained in the first component (PC 1) and $25.93 \%$ in the second component (PC 2); totaling $98.96 \%$ of the variance explained in the first two dimensions. The highest eigenvector values in the first two axes, represented by the vector arrows in Figure 2, were the cross-sectional areas of the adductor mandibulae (CSA AM), sternohyoideus (CSA SH), and epaxialis muscles (CSA Epax). The majority of species fell within a single cluster with larger species appearing as outliers.

The Discriminant Function Analysis revealed a clear distinction among the feeding modes (Figure 3). Four morphological traits were responsible for the discrimination of feeding modes: mechanical advantage for jaw closing, jaw opening and neurocranial rotation, and suction index. The first axis contributed $77.69 \%$ of the variance for discriminating the three feeding modes, with the three mechanical advantages serving as the main discerning factors. The second axis contributed $22.31 \%$ of the variance, with the mechanical advantage of the jaw opening and closing, along with the suction index as the discerning factors. Results of the predictive DFA, shown in Table 2, corroborated the a priori classification of the species into their respective feeding modes, with $90.9 \%$ of species assigned to the feeding modes appropriately. Centropristis striata and Haemulon plumieri were designated as ram-feeders, based on their morphological traits, differing from the original assignment into the suction and manipulation feeding mode respectively.

\section{Discussion}

It is conceivable that partitioning of food resources (and perhaps microhabitat) may help drive the coexistence of several species along the Atlantic coast of Florida (USA). Furthermore, empirical evidence indicates that the disparity in the mode of prey-capture (i.e., suction, ram or manipulation) is shaped by the constraint imposed by the functional-morphological design of the feeding apparatus of fishes. The high eigenvalues associated with the cross-sectional area of the three muscle groups underscores the relative importance force-generating capability in shaping the morphospace of feeding mechanics. While cross-sectional area is only one of the traits that impact force generation, it has been demonstrated to serve as a major contributor to force production [26]. It is plausible that muscle properties are a predominant contributor to the variation in feeding ability among teleost fishes. In fish-feeding systems, skeletal-muscles produce force and along with the mechanical advantage of the lower jaw, hyoid and neurocranial rotation drive cranial movement during feeding. In complex biomechanical systems such as buccal expansion, muscle use is modulated based on behavioral and environmental factors [6, 27].

The DFA further confirmed that morphological traits constrain prey use through their influence on feeding mode or prey-capture techniques. It is noteworthy that the mechanical advantages of the jaw and neurocranial mechanisms, as well as the Suction Index underlie the classification of the species into the three feeding modes. An elaboration of the relevance of these parameters to the feeding performance of fishes adds credence to the patterns of correlation between functional morphology and feeding mode that resulted from our analyses. Mechanical advantage of the feeding mechanism indicates the tradeoff between force transmission and speed of movement during feeding [2, $6,22,23]$. Manipulators, fish that bite or crush hard-shelled prey like Calamus penna and Balistes vetula, have a feeding mechanism that is designed for force production. Their feeding apparatus is equipped with hypertrophied jaw-adductor muscles to produce the massive force that is required to crush and process prey with hard exoskeletons or bite off pieces from prey too large for their gape [28-31]. Furthermore, effective transmission of force produced by these hypertrophied adductor muscles to the crushing or biting surfaces is facilitated by the high mechanical advantage of the lower jaws. Robust jaw-bones of manipulators resist the force of compression experienced while these hard-shelled prey organisms are crushed and reduced before swallowing [1, 30, 31]. In contrast, the premium features of the feeding mechanism of suction- and ram-feeding fishes, like Myctoperca microlepis and Centropristis striata, are the capability to produce high subambient pressure in the buccal cavity and fast movement of the jaws that are necessary to capture soft, but elusive prey organisms $[5-6,16]$. These requirements are facilitated by the feeding mechanism having a low mechanical advantage of the lower jaw and neurocranial rotation.

While suction index (SI) served as a discriminant among feeding groups, its variation among groups suggests a pattern that is inconsistent with the expected patterns that had been previously established in centrarchid fishes [16]. The pattern of variation in SI among the assemblage of fishes in this study indicates that suction- and ram-feeders have lower SI values compared to high values for manipulation-feeders. The SI model was originally developed using centrarchid fishes, focusing on the epaxialis as the main muscle group used to expand the buccal cavity during feeding. In addition, it also models the relationship between the field where suction force is applied and the rate of flow of water (plus prey) into the buccal cavity $[8,16,17]$. The SI appropriately predicts the suction-feeding capacity of free swimming planktivores and suction feeders, such as the centrarchid fish, Lepomis macrochirus, which has a small gape, large buccal cavity and a large cross-sectional area of the epaxialis, contributing to the large SI value. The SI is a strong predictor of feeding mode in the monophyletic centrarchid fishes [16]. It is interesting to note that this is not the case for the marine fishes included in this study. In marine fishes many 
suction-feeding fishes are reef dwelling ambush predators, such as groupers, which have large gape and low mechanical advantage of neurocranial rotation. This body shape produces very low SI values. It is conceivable that the evolutionary history of the fishes included in analyses involving the SI may confound the results showing the relationship between SI and food habits of fishes. The confounding effects of phylogeny in ecomorphological analyses will be included in our future analyses of a much larger number of species and corresponding food habits. Nonetheless, the suction index remains to be a strong determinant of the relationship between morphology and ecology in fishes.

Results of these analyses provide empirical evidence of the tight link between morphology and ecology. Appropriately defining the morphology-ecology (i.e., form and biological role) coupling furthers our understanding of the evolution of feeding mechanisms and the community structure of fishes $[1-3,5,17]$. The analyses revealed several constraints to prey use in the feeding apparatus that drive the determination of feeding mode. These constraints help define the potential niche of fishes in a community. Furthermore, pressure from changes in the environment will select for morphologies that optimize organismal performance in current conditions and ultimately drive diversification. Understanding diversity in morphology provides insight into the functional basis of community interactions.

\section{Acknowledgements}

This study was made possible by the Liebratore family who provided transportation and gear to collect specimens. Additional thanks to the FishLab at the Florida Institute of Technology for their support and feedback. Lastly thanks to Corianne Conway for providing photographs. 


\section{Appendix}

Appendix 1: Species means \pm standard error of the mean for each variable in the study. $\mathrm{FGC}=$ force generating capability, $\mathrm{AM}=$ adductor mandibulae, $\mathrm{SH}=$ sternohyoideus, $\mathbf{C S A}=$ cross-sectional area, $\mathrm{NCR}=$ neurocranial rotation.

\begin{tabular}{|c|c|c|c|c|c|c|c|c|c|c|c|c|c|c|c|c|c|c|}
\hline Species & $\mathrm{N}$ & $\begin{array}{c}\begin{array}{c}\text { Standard } \\
\text { Length }(\mathrm{mm})\end{array} \\
\end{array}$ & Suction Index & $\begin{array}{c}\text { Gape Width } \\
(\mathrm{mm})\end{array}$ & $\begin{array}{c}\text { Buccal } \\
\text { Length }(\mathrm{mm})\end{array}$ & $\begin{array}{c}\begin{array}{c}\text { Mech. Adv. } \\
\text { NCR }\end{array} \\
\end{array}$ & $\begin{array}{c}\text { CSA Epax } \\
\left(\mathrm{mm}^{2}\right) \\
\end{array}$ & $\operatorname{FGCAM}(\mathrm{N})$ & AM Mass (g) & $\begin{array}{c}\text { Ang. Pin. AM } \\
\left({ }^{\circ}\right)\end{array}$ & $\begin{array}{l}\text { CSA AM } \\
\left(\mathrm{mm}^{2}\right) \\
\end{array}$ & $\begin{array}{l}\text { Mech. Adv. } \\
\text { Closing } \\
\end{array}$ & FGC SH (N) & SH Mass (g) & $\begin{array}{c}\text { Ang. Pin. SH } \\
\left({ }^{\circ}\right)\end{array}$ & $\begin{array}{l}\text { CSAAM } \\
\left(\mathrm{mm}^{2}\right) \\
\end{array}$ & $\begin{array}{c}\text { Mech. Adv. } \\
\text { Opening }\end{array}$ & Jaw Mass (g) \\
\hline Balistes vetula & 1 & 291 & 0.64 & 22.0 & 59.0 & 0.83 & 999 & 13.59 & 9.93 & 23.45 & 591 & 0.35 & 31.17 & 10.65 & 15.63 & 363 & 0.42 & 1.2 \\
\hline Opsanus tau & 1 & 164 & 0.02 & 41.0 & 52.0 & 0.12 & 360 & 4.49 & 2.76 & 45.41 & 305 & 0.25 & 7.11 & 1.75 & 30.27 & 65.5 & 0.1 & 0.82 \\
\hline Caranx ruber & 3 & $397 \pm 25.6$ & $0.12 \pm 0.08$ & $49.0 \pm 3.00$ & $81.3 \pm 5.46$ & $0.31 \pm 0.07$ & $1591 \pm 330$ & $9.69 \pm 1.56$ & $3.80 \pm 0.61$ & $22.91 \pm 2.96$ & $257 \pm 76.8$ & $0.61 \pm 0.01$ & $13.19 \pm 3.17$ & $6.73 \pm 1.45$ & $21.98 \pm 3.87$ & $431 \pm 64.8$ & $0.19 \pm 0.02$ & $2.27 \pm 0.46$ \\
\hline Seriola dumerili & 3 & $462 \pm 27.9$ & $0.08 \pm 0.01$ & $67.7 \pm 6.43$ & $103.6 \pm 2.84$ & $0.27 \pm 0.03$ & $1964 \pm 120$ & $11.71 \pm 1.65$ & $7.33 \pm 0.78$ & $24.65 \pm 4.23$ & $751 \pm 35.7$ & $0.62 \pm 0.02$ & $10.64 \pm 1.70$ & $10.93 \pm 2.21$ & $20.61 \pm 1.39$ & $879 \pm 9.50$ & $0.20 \pm .002$ & $3.77 \pm 0.62$ \\
\hline Coryphaena hippurus & 3 & $707 \pm 66.4$ & $0.06 \pm 0.01$ & $69.0 \pm 7.23$ & $89.6 \pm 11.97$ & $0.21 \pm 0.04$ & $1771 \pm 475$ & $31.22 \pm 9.29$ & $11.68 \pm 3.25$ & $37.62 \pm 1.72$ & $561 \pm 166$ & $0.56 \pm 0.02$ & $7.93 \pm 1.36$ & $3.37 \pm 1.23$ & $32.92 \pm 3.16$ & $218 \pm 68.6$ & $0.15 \pm .004$ & $7.28 \pm 2.22$ \\
\hline Haemulon aurolineatum & 11 & $168 \pm 4.59$ & $0.20 \pm 0.02$ & $17.4 \pm 1.21$ & $45.18 \pm 1.74$ & $0.32 \pm 0.02$ & $490 \pm 38.3$ & $3.38 \pm 0.42$ & $0.46 \pm 0.04$ & $35.78 \pm 1.78$ & $65.5 \pm 9.27$ & $0.48 \pm 0.01$ & $1.84 \pm 0.13$ & $0.58 \pm 0.06$ & $33.86 \pm 1.10$ & $105 \pm 13.3$ & $0.20 \pm 0.01$ & $0.40 \pm 0.04$ \\
\hline Haemulon plumieri & 2 & 175 & $0.15 \pm 0.03$ & $17.0 \pm 3.00$ & $38.5 \pm 7.50$ & $0.23 \pm 0.001$ & $414 \pm 72$ & $6.22 \pm 0.66$ & $0.82 \pm 0.25$ & $27.31 \pm 1.78$ & $55.2 \pm 25.1$ & $0.42 \pm 0.08$ & $5.74 \pm 0.77$ & $1.62 \pm 0.57$ & $23.65 \pm 5.44$ & $144 \pm 30.5$ & $0.29 \pm 0.02$ & $0.38 \pm 0.13$ \\
\hline Haemulon sciurus & 5 & $175 \pm 3.26$ & $0.16 \pm 0.02$ & $18.8 \pm 1.59$ & $50.4 \pm 1.03$ & $0.27 \pm 0.02$ & $543 \pm 52.3$ & $4.89 \pm 0.56$ & $0.97 \pm 0.07$ & $30.70 \pm 1.93$ & $102 \pm 15.0$ & $0.47 \pm 0.01$ & $3.93 \pm 0.23$ & $1.67 \pm 0.09$ & $29.26 \pm 2.90$ & $203 \pm 20.2$ & $0.21 \pm 0.01$ & $0.57 \pm 0.06$ \\
\hline Lutjanus analis & 1 & 380 & 0.12 & 46.0 & 72.0 & 0.28 & 1476 & 15.74 & 6.32 & 33.00 & 521 & 0.51 & 10.74 & 11.4 & 22.00 & 985 & 0.2 & 1.8 \\
\hline Lutjanus griseus & 2 & $283 \pm 39.0$ & $0.12 \pm 0.05$ & $43.0 \pm 2.00$ & $67.5 \pm 6.50$ & $0.29 \pm 0.04$ & $1206 \pm 513$ & $14.35 \pm 6.91$ & $4.48 \pm 1.19$ & $40.33 \pm 5.85$ & $627 \pm 269$ & $0.50 \pm 0.02$ & $10.05 \pm 4.33$ & $6.95 \pm 2.42$ & $32.64 \pm 1.85$ & $594 \pm 202$ & $0.19 \pm 0.01$ & $1.44 \pm 0.44$ \\
\hline Lutjanus synagris & 6 & $266 \pm 8.60$ & $0.19 \pm 0.04$ & $39.3 \pm 1.58$ & $63.0 \pm 2.50$ & $0.54 \pm 0.08$ & $880 \pm 146$ & $7.48 \pm 0.67$ & $2.20 \pm 0.28$ & $28.17 \pm 152$ & $195 \pm 35.7$ & $0.49 \pm 0.01$ & $7.99 \pm 0.29$ & $4.30 \pm 0.63$ & $26.08 \pm 1.44$ & $454 \pm 83.5$ & $0.19 \pm .004$ & $0.94 \pm 0.12$ \\
\hline Ocyurus chrysurus & 1 & 410 & 0.1 & 36.0 & 56.0 & 0.20 & 1008 & 6.33 & 1.97 & 31.74 & 172 & 0.56 & 8.37 & 5.62 & 21.16 & 542 & 0.16 & 0.8 \\
\hline Rachycentron canadum & 3 & $873 \pm 46.9$ & $0.02 \pm .001$ & $100.3 \pm 7.26$ & $185.6 \pm 10.4$ & $0.07 \pm 0.01$ & $5237 \pm 198$ & $33.51 \pm 11.20$ & $24.86 \pm 7.98$ & $26.35 \pm 1.28$ & $1073 \pm 197$ & $0.59 \pm .003$ & $14.57 \pm 2.03$ & $13.64 \pm 2.80$ & $24.11 \pm 3.48$ & $589 \pm 69.1$ & $0.18 \pm .005$ & $18.9 \pm 2.62$ \\
\hline Euthynnus alletteratus & 2 & $495 \pm 43.0$ & $0.15 \pm 0.04$ & $40.5 \pm 9.50$ & $99.5 \pm 0.28$ & $0.28 \pm 0.05$ & $2042 \pm 337$ & $14.84 \pm 3.50$ & $3.32 \pm 1.05$ & $27.91 \pm 3.07$ & $241 \pm 3.58$ & $0.64 \pm 0.03$ & $6.60 \pm 0.77$ & $3.64 \pm 1.32$ & $22.75 \pm 2.10$ & $146 \pm 16.4$ & $0.08 \pm 0.02$ & $1.90 \pm 0.53$ \\
\hline Scomberomorus maculatus & 4 & $369 \pm 15.8$ & $0.04 \pm .004$ & $31.2 \pm 1.55$ & $64.25 \pm 4.03$ & $0.23 \pm 0.02$ & $392 \pm 56.0$ & $2.78 \pm 0.43$ & $0.64 \pm 0.09$ & $23.23 \pm 1.15$ & $149 \pm 27.4$ & $0.51 \pm 0.03$ & $2.19 \pm 0.36$ & $0.53 \pm 0.06$ & $21.55 \pm 2.28$ & $63.2 \pm 5.37$ & $0.10 \pm 0.01$ & $0.49 \pm 0.09$ \\
\hline Centropristis striata & 10 & $288 \pm 19.9$ & $0.11 \pm 0.01$ & $53.9 \pm 3.69$ & $70.8 \pm 5.12$ & $0.29 \pm 0.02$ & $1348 \pm 123$ & $11.96 \pm 1.36$ & $4.33 \pm 0.77$ & $26.41 \pm 1.97$ & $370 \pm 54.6$ & $0.60 \pm 0.01$ & $12.62 \pm 1.42$ & $7.57 \pm 1.32$ & $26.05 \pm 2.14$ & $528 \pm 93.2$ & $0.18 \pm .001$ & $1.99 \pm 0.33$ \\
\hline Epinephelus drummonhayi & 2 & $390 \pm 12.0$ & $0.06 \pm 0.01$ & $71.0 \pm 2.00$ & $100.5 \pm 8.5$ & $0.29 \pm 0.03$ & $1539 \pm 113$ & $24.36 \pm 5.33$ & $7.81 \pm 0.23$ & $31.04 \pm 1.16$ & $542 \pm 98.9$ & $0.56 \pm 0.01$ & $20.22 \pm 1.67$ & $12.43 \pm 1.64$ & $25.67 \pm 4.21$ & $502 \pm 178$ & $0.20 \pm .005$ & $3.73 \pm 0.05$ \\
\hline Mypteroperca microlepis & 1 & 662 & 0.02 & 122 & 176.0 & 0.19 & 2652 & 53.15 & 50.34 & 28.26 & 3357 & 0.56 & 47.53 & 68.99 & 18.84 & 3125 & 0.17 & 24.47 \\
\hline Calamus bajonado & 5 & $269 \pm 8.88$ & $0.19 \pm 0.06$ & $29.6 \pm 2.15$ & $57.2 \pm 2.26$ & $0.25 \pm 0.03$ & $1141 \pm 174$ & $13.21 \pm 1.27$ & $3.86 \pm 0.76$ & $31.85 \pm 1.33$ & $295 \pm 97.3$ & $0.34 \pm 0.01$ & $12.93 \pm 1.81$ & $3.53 \pm 0.60$ & $29.88 \pm 2.47$ & $246 \pm 47.8$ & $0.32 \pm 0.02$ & $2.62 \pm 0.44$ \\
\hline Calamus penna & 9 & $224 \pm 9.07$ & $0.41 \pm 0.05$ & $24.5 \pm 1.37$ & $46.3 \pm 2.63$ & $0.37 \pm 0.03$ & $1226 \pm 106$ & $10.04 \pm 0.98$ & $3.29 \pm 0.46$ & $31.53 \pm 1.35$ & $236 \pm 45.8$ & $0.35 \pm 0.01$ & $9.49 \pm 0.98$ & $2.82 \pm 0.38$ & $30.20 \pm 1.63$ & $225 \pm 25.8$ & $0.38 \pm 0.01$ & $1.67 \pm 0.26$ \\
\hline Calamus proridens & 2 & $261 \pm 21.0$ & $0.42 \pm 0.08$ & $29.5 \pm 2.50$ & $50.5 \pm 2.50$ & $0.39 \pm 0.07$ & $1571 \pm 167$ & $14.21 \pm 2.98$ & $3.63 \pm 0.54$ & $28.98 \pm 3.08$ & $163 \pm 21.5$ & $0.32 \pm .003$ & $13.46 \pm 0.99$ & $4.25 \pm 0.22$ & $23.64 \pm 2.26$ & $242 \pm 20.1$ & $0.39 \pm 0.03$ & $1.56 \pm 0.38$ \\
\hline Pagrus pagrus & 2 & $272 \pm 12.0$ & $0.28 \pm 0.01$ & $30.0 \pm 1.00$ & $57.0 \pm 3.00$ & $0.32 \pm 0.03$ & $1526 \pm 196$ & $10.35 \pm 1.54$ & $4.28 \pm 1.15$ & $25.12 \pm 1.39$ & $319 \pm 52.2$ & $0.36 \pm 0.01$ & $8.52 \pm 0.30$ & $3.64 \pm 1.23$ & $21.62 \pm 4.88$ & $255 \pm 124$ & $0.31 \pm 0.02$ & $1.2 \pm 0.21$ \\
\hline
\end{tabular}




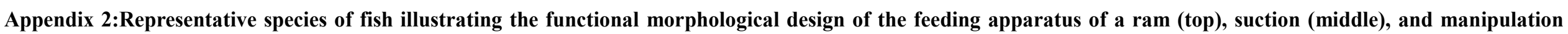
(bottom) feeding fish.
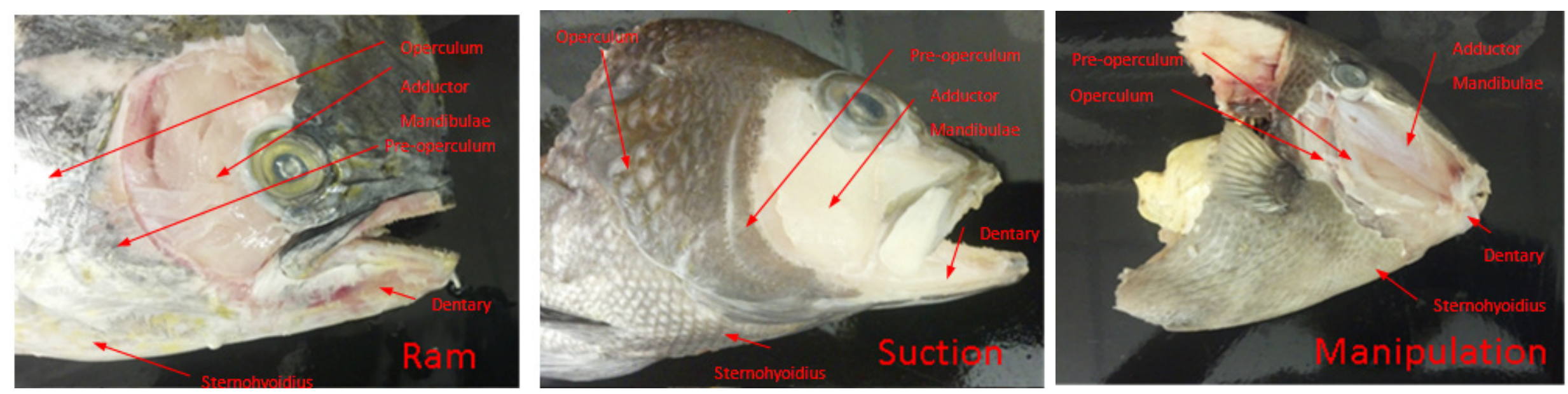


\section{REFERENCES}

[1] P.C. Wainwright. Morphology and ecology: functional basis of feeding constraints in Caribbean labrid fishes, Ecology, Vol. 69, No. 3, 635-645, 1988.

[2] P.C. Wainwright, B.R. Richard. Predicting patterns of prey use from morphology of fishes, Environmental Biology of Fishes, Vol. 44, No. 1-3, 97-113, 1995.

[3] S.F. Norton, J.J. Luczkovich, P.J. Motta. The role of ecomorphological studies in the comparative biology of fishes, Environmental Biology of Fishes, Vol. 44, No. 1-3, 287-304, 1995.

[4] P.J. Motta, S.F. Norton, J.J. Luczkovich. Perspectives on the ecomorphology of bony fishes, Environmental Biology of Fishes, Vol. 44, No. 1-3, 11-22, 1995.

[5] P.C. Wainwright, D.R. Bellwood. Ecomorphology of feeding in coral reef fishes. In P.F. Sale, Coral Reef Fishes: Dynamics and Diversity in a Complex Ecosystem, Academic Press, New York, 33-55, 2002.

[6] K.F. Liem. Acquisition of energy by teleosts: adaptive mechanisms and evolutionary patterns. In M.A. Ali. Environmental Physiology of Fishes, Plenum Publishing, New York, 299-334, 1980.

[7] P.C. Wainwright, S.H. Huskey, R.G. Turingan, A.M. Carroll. Ontogeny of Suction Feeding Capacity in Snook, Centropomus undecimalis, Journal of Experimental Zoology, Vol. 305A, No. 3, 246-252, 2006.

[8] P.C. Wainwright, A.M. Carrol, D.C. Collar, S.W. Day, T.E. Higham, R.A. Holzman. Suction feeding mechanics, performance, and diversity in fishes, Inegrative and Comparative Biology, Vol. 47, No. 1, 96-106, 2007.

[9] J.E. Randall. Food habits of reef fishes of the West Indies. Studies in Tropical Oceanography, Vol. 5, 665-847, 1967.

[10] B.S. Haplin, S.R. Floeter. Functional diversity responses to changing species richness on reef fish communities, Marine Ecological Progress Series, Vol. 364, 147-156, 2008.

[11] C. Papaconstantinou, E. Caragitsou. Feeding interactions between two sympatric species Pagrus pagrus and Phycis phycis around Kastellorizo island (Dodecanese, Greece), Fisheries Research, Vol. 7, 329-342, 1989.

[12] C.D. Rose, W.W. Hassler. Food habits and sex ratios of dolphin Coryphaena hippurus captured in the western Atlantic Ocean off Hatteras, North Carolina, Trans. Am. Fish. Soc. Vol. 103, No. 1, 94-100, 1974.

[13] R.E. Bowman, C.E. Stillwell, W.L. Michaels, M.D. Grosslein. Food of northwest Atlantic fishes and two common species of squid. NOAA Tech. Memo. NMFS-NE 155, 1-138, 2000.

[14] P.B. Hood, M.F. Godcharles, R.S. Barco. Age, Growth, Reproduction, and the feeding ecology of black sea bass, Centropristis striata (pisces: serranidae), in the Eastern Gulf of Mexico, Bulletin of Marine Science, Vol. 54, No. 1, 24-37, 1994.

[15] M.D. Mullany. Ontogenetic shifts in the diet of Gag, Mycteroperca microlepis, (Goode and Bean),(Pisces: Serranidae), Proceedings of the 43rd Gulf and Caribean Fisheries Institute, 1994.
[16] A.M. Carroll, P.C. Wainwright, S.H. Huskey, D.C. Collar, R.G. Turingan. Morphology predicts suction feeding performance in centrarchid fishes, Journal of Experimental Biology. Vol. 207, No. 22, 3873-3881, 2004.

[17] D.C. Collar, P.C. Wainwright. Discordance Between Morphological and Mechanical Diversity in the Feeding Mechanism of Centrarchid Fishes, Evolution, Vol. 60, No. 12, 2575-2584, 2006.

[18] L.J. Calow, R.M. Alexander. A mechanical analysis of the hind limb of a frog (Rana temporaria), Journal of Zoology, Vol. 171, No. 3, 293-321, 1973.

[19] A.G. Lowndes. Density of Fishes. Some notes on the swimming of fish to be correlated with density, sinking factor, and the load carried. Annals and Magazine of Natural History, Vol. 8, 241-256, 1955.

[20] J.D. Altringham, I.A. Johnston. The pCa-tension and force-velocity characteristics of skinned fibers isolated from fish fast and slow muscle, Journal of Physiology, Vol. 333, 421-449, 1982 .

[21] I.A. Johnston, J. Salamonski. Power output and force-velocity relationship of red and white muscle fibers from the Pacific blue marlin (Makria nigricans), Journal of Experimental Biology, Vol. 111, 171-177, 1984.

[22] M.W. Westneat. Transmission of force and velocity in the feeding mechanisms of labrid fishes (Teleostei, Perciformes), Zoomorphology, Vol. 114, No. 2, 103-118, 1994.

[23] P.C. Wainwright, D.R. Bellwood, M.W. Westneat, J. R. Grubich, A.S. Hoey. A functional morphospace for the skull of labrid fishes: patterns of diversity in a complex biomechanical system. Biological Journal of the Linnean Society, Vol. 82, No. 1, 1-25, 2004.

[24] R Core Team. A language and environment for statistical computing, R Foundation for Statistical Computing, Austria, 2012 .

[25] W.N. Venerables, B.D. Ripley. Modern Applied Statistics with S. Springer, New York, 2002.

[26] K. Schmidt-Nielsen. Scaling: why is animal size is so important? Cambridge University Press, Great Britain, 1984.

[27] F. Galis, A. Terlouw, W.M. Osse. The relation between morphology and behavior during ontogenetic and evolutionary changes, Journal of Fish Biology. Vol. 45, 13-26, 1994.

[28] R.G. Turingan, P.C. Wainwright. Morphological and functional bases of durophagy in the Queen Triggerfish, Balistes vetula (Pisces, Tetradontiformes). Journal of Morphology. Vol. 215, No. 2, 101-118, 1993.

[29] R.G Turingan. Ecomorphological relationships among Caribbean tetradontiform fishes. Journal of Zoology, Vol. 233, No. 3, 493-521, 1994.

[30] R.G. Turingan, P.C. Wainwright, D.A. Hensley. Interpopulation variation in prey use and feeding biomechanics in Caribbean triggerfishes. Oecologia, Vol. 102, No. 3, 296-304, 1995.

[31] M.M. Cutwa, R.G. Turingan. Intralocality variation in feeding biomechanics and prey use in Archosargus probatocephalus (Teleostei, Sparidae), with implications for the ecomorphology of fishes. Environmental Biology of Fishes, Vol. 59, No. 2, 191-198, 2000. 